\title{
Alemtuzumab CARE-MS II 5-year follow-up
}

Efficacy and safety findings

\section{OPEN}

Alasdair J. Coles, MD, $\mathrm{PhD}$

Jeffrey A. Cohen, MD

Edward J. Fox, MD, PhD

Gavin Giovannoni, MD,

$\mathrm{PhD}$

Hans-Peter Hartung,

$\mathrm{MD}, \mathrm{PhD}$

Eva Havrdova, MD, PhD

Sven Schippling, MD

Krzysztof W. Selmaj, $\mathrm{MD}, \mathrm{PhD}$

Anthony Traboulsee, MD

D. Alastair S. Compston, PhD, FRS

David H. Margolin, MD, $\mathrm{PhD}$

Karthinathan Thangavelu, $\mathrm{PhD}$

Madalina C. Chirieac, $\mathrm{MD}, \mathrm{MPH}$

Darlene Jody, MD

Panos Xenopoulos, $\mathrm{PhD}$

Richard J. Hogan, PhD

Michael A. Panzara, MD, $\mathrm{MPH}$

Douglas L. Arnold, MD

On behalf of CARE-MS

II and CAMMS03409

Investigators

Correspondence to

Dr. Coles:

ajc1020@medschl.cam.ac.uk

Editorial, page 1098

See page 1107

Supplemental data at Neurology.org

\section{ABSTRACT}

Objective: To evaluate 5-year efficacy and safety of alemtuzumab in patients with active relapsing-remitting multiple sclerosis and inadequate response to prior therapy.

Methods: In the 2-year Comparison of Alemtuzumab and Rebif Efficacy in Multiple Sclerosis (CARE-MS) II study (NCT00548405), alemtuzumab-treated patients received 2 courses (baseline and 12 months later). Patients could enter an extension (NCT00930553), with as-needed alemtuzumab retreatment for relapse or MRI activity. Annualized relapse rate (ARR), 6-month confirmed disability worsening (CDW; $\geq 1$-point Expanded Disability Status Scale [EDSS] score increase [ $\geq 1.5$ if baseline EDSS $=0$ ]), 6-month confirmed disability improvement (CDI; $\geq 1$-point EDSS decrease [baseline score $\geq 2.0]$ ), no evidence of disease activity (NEDA), brain volume loss $(B \vee L)$, and adverse events (AEs) were assessed.

Results: Most alemtuzumab-treated patients (92.9\%) who completed CARE-MS II entered the extension; 59.8\% received no alemtuzumab retreatment. ARR was low in each extension year (years 3-5: $0.22,0.23,0.18)$. Through 5 years, $75.1 \%$ of patients were free of 6 -month CDW; $42.9 \%$ achieved 6-month CDI. In years 3, 4, and 5, proportions with NEDA were 52.9\%, 54.2\%, and $58.2 \%$, respectively. Median yearly BVL remained low in the extension (years 1-5: $-0.48 \%$, $-0.22 \%,-0.10 \%,-0.19 \%,-0.07 \%)$. AE exposure-adjusted incidence rates in the extension were lower than in the core study. Thyroid disorders peaked at year 3, declining thereafter.

Conclusions: Alemtuzumab provides durable efficacy through 5 years in patients with an inadequate response to prior therapy in the absence of continuous treatment.

Classification of evidence: This study provides Class III evidence that alemtuzumab provides efficacy and slowing of brain atrophy through 5 years. Neurology ${ }^{\circledR} 2017 ; 89: 1117-1126$

\section{GLOSSARY}

$\mathbf{A E}=$ adverse event; $\mathbf{A R R}=$ annualized relapse rate; $\mathbf{B P F}=$ brain parenchymal fraction; $\mathbf{B V L}=$ brain volume loss; $\mathbf{C A R E}-\mathbf{M S}$ II = Comparison of Alemtuzumab and Rebif Efficacy in Multiple Sclerosis II; CDI = confirmed disability improvement; CDW = confirmed disability worsening; $\mathbf{C l}=$ confidence interval; DMT = disease-modifying therapy; $\mathbf{E A I R}=$ exposure-adjusted incidence rate; EDSS = Expanded Disability Status Scale; $\mathbf{G d}=$ gadolinium; IAR = infusion-associated reaction; IFN- $\boldsymbol{\beta}-\mathbf{1} \mathbf{a}=$ interferon $\beta-1 a$; ITP = immune thrombocytopenia; MS = multiple sclerosis; NEDA = no evidence of disease activity; RRMS = relapsingremitting multiple sclerosis; $\mathbf{S C}=$ subcutaneous.

Alemtuzumab (LEMTRADA; Sanofi Genzyme, Cambridge, MA) is a humanized monoclonal antibody that depletes circulating lymphocytes by selectively targeting CD52, which is expressed at high levels on $\mathrm{T}$ and B lymphocytes. Depletion is followed by a characteristic pattern of

From the Department of Clinical Neurosciences (A.J.C., D.A.S.C.), University of Cambridge, UK; Mellen Center (J.A.C.), Cleveland Clinic, OH; MS Clinic of Central Texas (E.J.F.), Central Texas Neurology Consultants, Round Rock; Queen Mary University of London (G.G.), Barts and the London School of Medicine, UK; Department of Neurology and Center for Neuropsychiatry (H.-P.H.), Medical Faculty, Heinrich-Heine University, Düsseldorf, Germany; Department of Neurology and Center for Clinical Neuroscience (E.H.), First Faculty of Medicine, Charles University and General Hospital in Prague, Czech Republic; Neuroimmunology and Multiple Sclerosis Research, Department of Neurology (S.S.), University Hospital Zürich and University of Zürich, Switzerland; Department of Neurology (K.W.S.), Medical University of Łódź, Poland; The University of British Columbia (A.T.), Vancouver, Canada; Sanofi (D.H.M., K.T., M.C.C., D.J., M.A.P.), Cambridge, MA; Envision Scientific Solutions (P.X.), Philadelphia, PA; Envision Scientific Solutions (R.J.H.), Sydney, NSW, Australia; NeuroRx Research (D.L.A.), Montréal; Department of Neurology and Neurosurgery (D.L.A.), Montréal Neurological Institute, McGill University, Québec, Canada. M.A.P. is currently affiliated with Wave Life Sciences, Cambridge, MA.

Coinvestigators are listed at Neurology.org.

Go to Neurology.org for full disclosures. Funding information and disclosures deemed relevant by the authors, if any, are provided at the end of the article. The Article Processing Charge was funded by Sanofi.

This is an open access article distributed under the terms of the Creative Commons Attribution-NonCommercial-NoDerivatives License 4.0 (CC BY-NC-ND), which permits downloading and sharing the work provided it is properly cited. The work cannot be changed in any way or used commercially without permission from the journal. 
lymphocyte repopulation and a cytokine expression shift toward a less inflammatory profile, both of which may contribute to durable efficacy. ${ }^{1,2}$ Currently, alemtuzumab is approved in over 60 countries for treatment of adults with relapsing-remitting multiple sclerosis (RRMS); in the European Union, it is approved for adults with active RRMS defined by clinical or imaging features, including treatment-naive patients, and, in the United States, it is generally reserved for patients who have had inadequate response to at least 2 drugs indicated for MS treatment. ${ }^{3-5}$

Efficacy and safety of alemtuzumab in patients with RRMS were evaluated in 3 raterblinded clinical trials. In the phase 2 CAMMS223 (NCT00050778) ${ }^{6}$ and the phase 3 Comparison of Alemtuzumab and Rebif Efficacy in Multiple Sclerosis I (CARE-MS I [NCT00530348]) $)^{7}$ studies of treatment-naive patients, and the CAREMS II (NCT00548405) ${ }^{8}$ trial of those with an inadequate response to prior therapy, alemtuzumab treatment was superior to subcutaneous interferon $\beta$-1a (SC IFN- $\beta-1 \mathrm{a}$; Rebif; EMD Serono Inc., Rockland, MA) on clinical and MRI outcomes. Significantly more alemtuzumab-treated patients achieved no evidence of disease activity (NEDA) in the 2-year, phase 3 studies, ${ }^{7,8}$ and brain volume loss (BVL) was significantly reduced with alemtuzumab in all 3 trials. ${ }^{6-8}$ The most frequent adverse events (AEs) with alemtuzumab were infusionassociated reactions (IARs); treatmentassociated autoimmune AEs were also observed. ${ }^{6-8}$ These trials demonstrated a positive benefit-risk profile of alemtuzumab.

This report presents interim efficacy and safety results through 3 years of an extension study (NCT00930553) in patients who received alemtuzumab during the core CARE-MS II trial (total of 5 years of follow-up).

METHODS Patients and procedures for the CARE-MS II core study. The design of the 2-year core study has been published previously. ${ }^{8}$ Briefly, CARE-MS II was a randomized, rater-blinded, active-controlled, head-to-head trial comparing alemtuzumab $12 \mathrm{mg}$ and SC IFN- $\beta-1 \mathrm{a}(44 \mu \mathrm{g} 3$ times per week) in patients with active disease ( $\geq 2$ relapses in the previous 2 years and $\geq 1$ relapse in the prior year) and inadequate response to prior therapy ( $\geq 1$ relapse while receiving IFN- $\beta$ or glatiramer acetate after $\geq 6$ months of treatment). Randomization into a third treatment arm (alemtuzumab $24 \mathrm{mg}$ ) was discontinued early and deemed exploratory for statistical purposes. Safety data from the $24-\mathrm{mg}$ arm are summarized in this report.

Procedures for the extension study. Alemtuzumab-treated patients who completed CARE-MS II could enroll in the extension and receive, at the investigator's discretion, additional alemtuzumab courses ( $12 \mathrm{mg}$ on 3 consecutive days) $\geq 48$ weeks after the most recent course, if they had evidence of MS disease activity ( $\geq 1$ protocol-defined relapse or $\geq 2$ new/ enlarging T2 hyperintense or gadolinium [Gd]-enhancing brain or spinal cord lesions on MRI). Retreatment-disqualifying criteria included, but were not limited to, pregnancy and diagnosis of immune thrombocytopenia (ITP) or other immune cytopenia. Decisions on whether to initiate retreatment in eligible patients, or to provide another licensed disease-modifying therapy (DMT), were left to the treating physicians and patients. Patients who received SC IFN- $\beta$ - 1 a for 2 years in the core study could also enroll in the extension and switch to alemtuzumab treatment; results for these patients will be reported separately.

Efficacy assessments. The Expanded Disability Status Scale (EDSS) was assessed by raters blinded throughout the extension to core study treatment assignment and treatment history. EDSS was assessed quarterly and for evaluation of suspected relapses. Relapse events required objective signs on examination, lasting $\geq 48$ hours, and were confirmed by the investigator. Annual MRI scans were analyzed by blinded imaging specialists at NeuroRx Research (Montréal, Canada [lesionbased analyses]) and the Cleveland Clinic MS MRI Analysis Center (Cleveland, $\mathrm{OH}$ [brain parenchymal fraction (BPF) analysis]).

Clinical efficacy endpoints included annualized relapse rate (ARR); proportion of relapse-free patients; 6-month confirmed disability worsening (CDW; $\geq 1.0$-point EDSS score increase from core study baseline [ $\geq 1.5$ if baseline EDSS score $=0]$ ); mean change from baseline EDSS score; proportions of patients with improved ( $\geq 1.0$-point decrease), worsened ( $\geq 1.0$-point increase), or stable ( $\leq 0.5$-point change) EDSS scores compared with baseline; and 3-, 6-, or 12-month confirmed disability improvement (CDI; $\geq 1.0$-point decrease from core study baseline EDSS score, in patients with baseline EDSS scores $\geq 2.0$ ).

MRI lesion assessments included proportions of patients with Gd-enhancing, new/enlarging T2 hyperintense, and new nonenhancing T1 hypointense lesions. Median percentage BVL from baseline and per year was calculated.

Absence of clinical disease activity (absence of both relapses and 6-month $\mathrm{CDW}$ ), absence of MRI lesion activity (absence of both new Gd-enhancing and new/enlarging T2 hyperintense lesions), and NEDA (absence of both clinical and MRI lesion activity) were assessed annually and cumulatively (sustained over years 3-5).

Safety monitoring. AEs, serious AEs, medical events of interest, and laboratory tests for thyroid function (at least quarterly), hematology (at least monthly), serum creatinine (monthly), and urinalysis with microscopy (monthly) were evaluated. All safety monitoring procedures continued until 4 years after last alemtuzumab administration, or until study end, whichever occurred later. IARs were defined as any $\mathrm{AE}$ with onset during infusion or $\leq 24$ hours postinfusion. 
Figure 1 Patient disposition

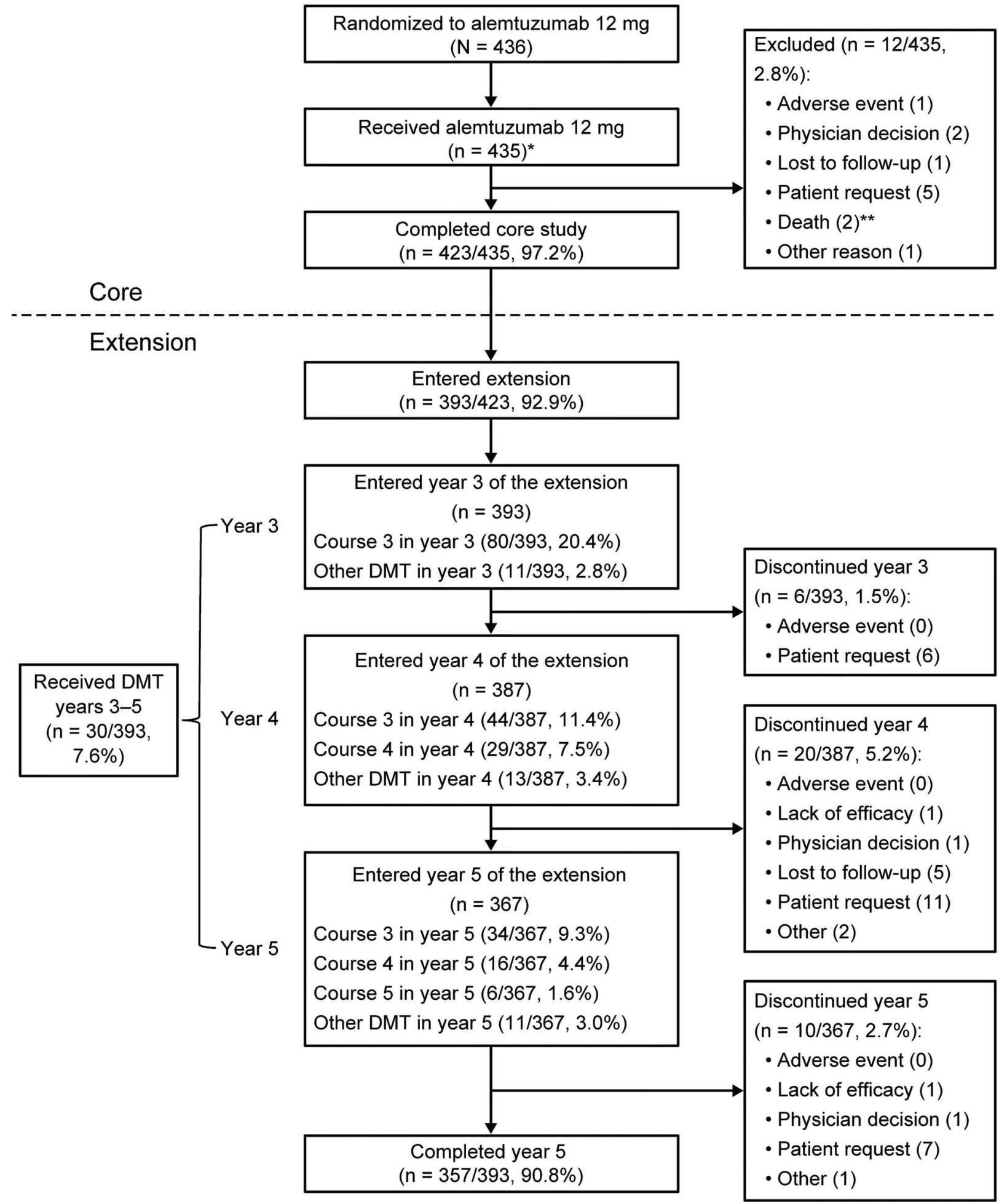

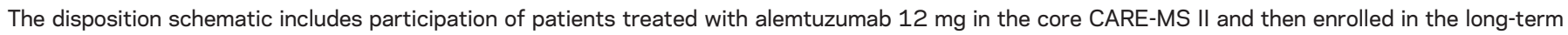

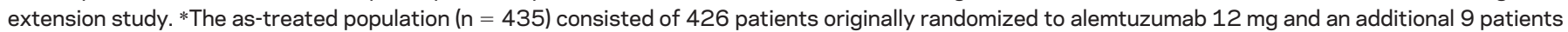

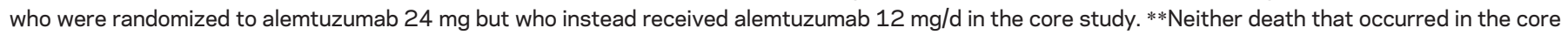
study was related to treatment. CARE-MS = Comparison of Alemtuzumab and Rebif Efficacy in Multiple Sclerosis; DMT = disease-modifying therapy.

Classification of evidence. We examined efficacy and safety with alemtuzumab through 5 years. This study provides Class III evidence that efficacy outcomes were maintained or further improved with alemtuzumab during extended follow-up in patients with active RRMS who had an inadequate response to prior therapy. Durable efficacy without continuous treatment was shown using several assessments including ARR, CDW, CDI, MRI lesion outcomes, NEDA, and slowing of BVL; most 
A

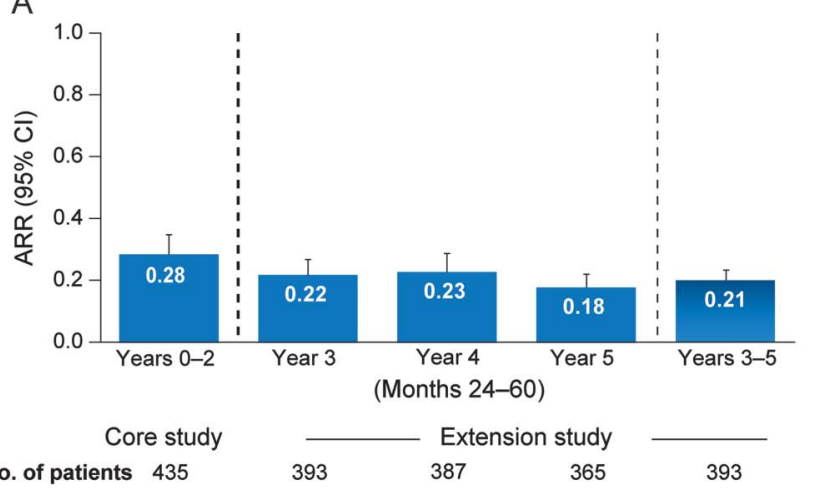

B

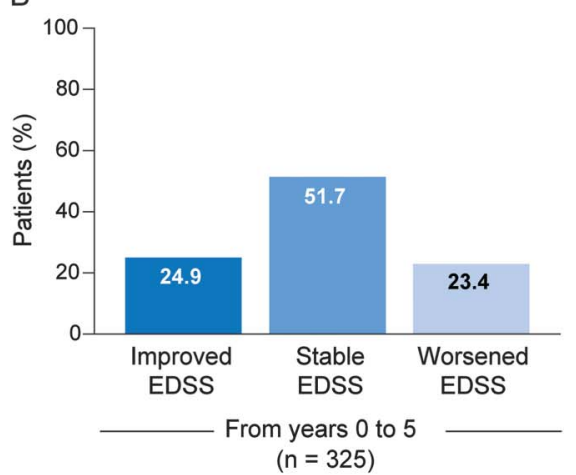

C

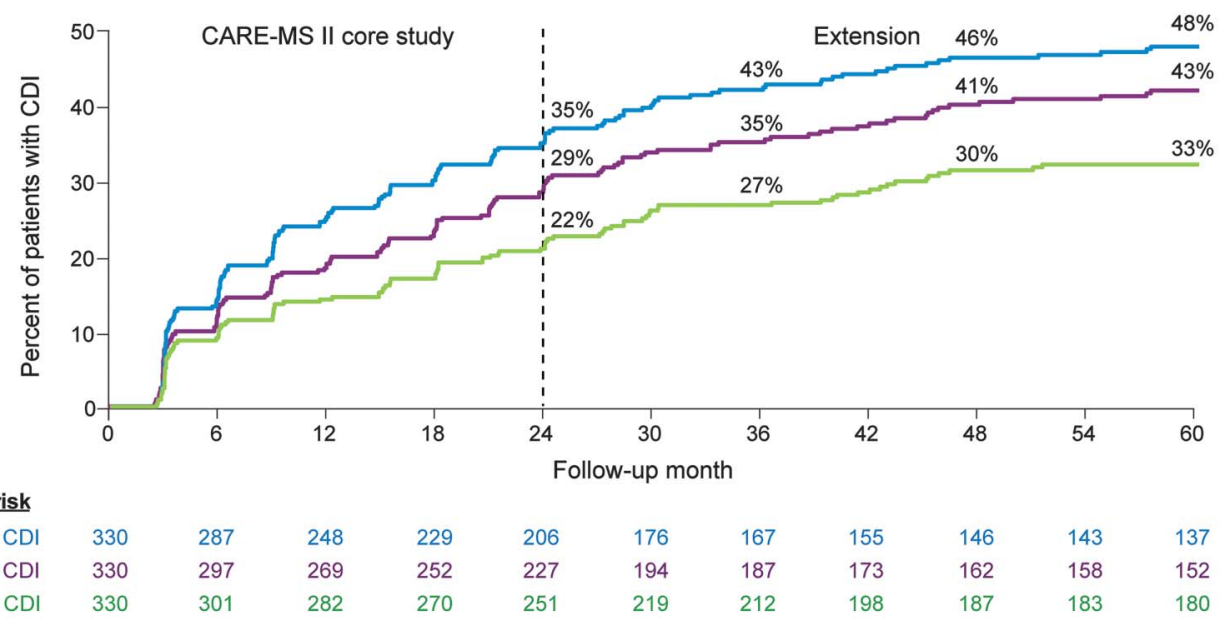

D
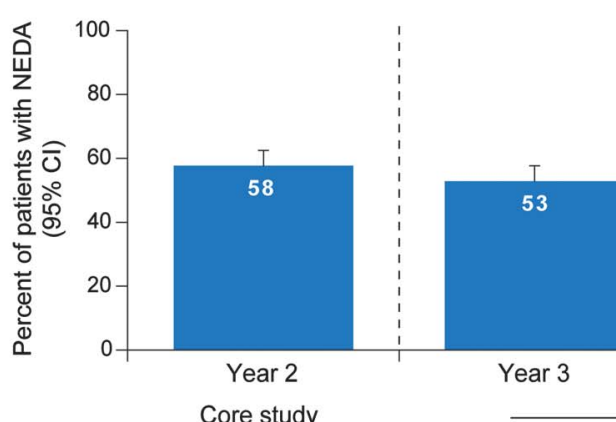

402

361

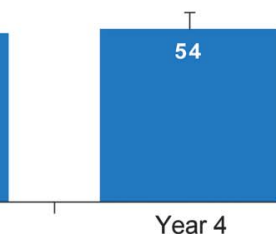

Extension study

No. of patients

\begin{tabular}{|ll}
\hline Free of relapse (\%) & 79 \\
Free of 6-month CDW (\%) & 92 \\
Free of clinical disease & 73 \\
activity (\%)
\end{tabular}

$$
\text { activity (\%) }
$$

\begin{tabular}{|lllll|}
\hline Gd-enhancing T1 lesion-free* (\%) & 91 & 87 & 89 & 90 \\
New/enlarging T2 lesion-free (\%) & 76 & 69 & 70 & 68 \\
Free of MRI lesion activity (\%) & 76 & 68 & 70 & 68 \\
\hline
\end{tabular}

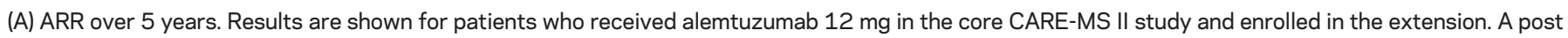

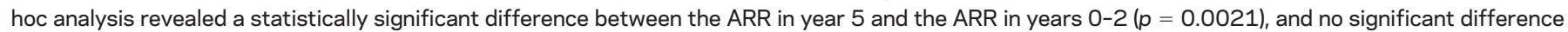

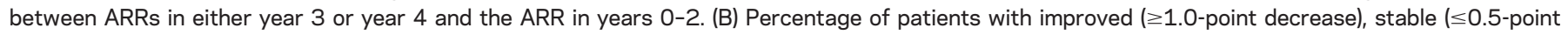

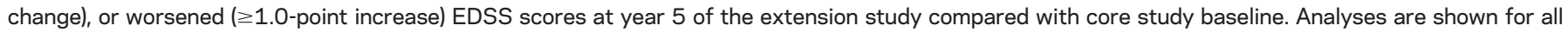

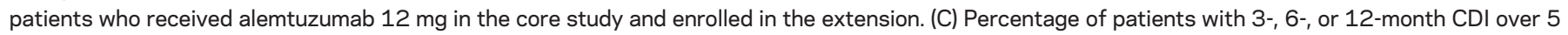

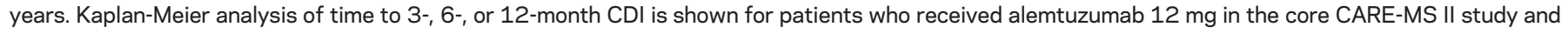

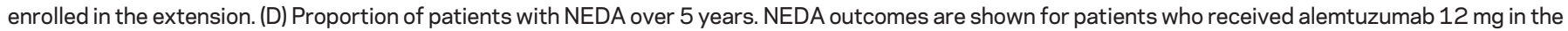

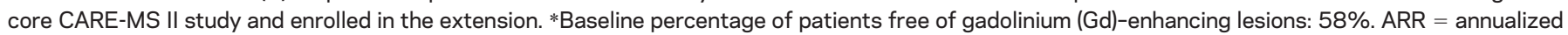

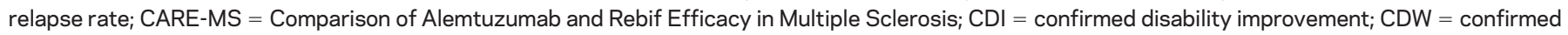
disability worsening; $\mathrm{Cl}$ = confidence interval; EDSS = Expanded Disability Status Scale; NEDA = no evidence of disease activity. 
Figure $3 \quad$ Brain volume loss over 5 years

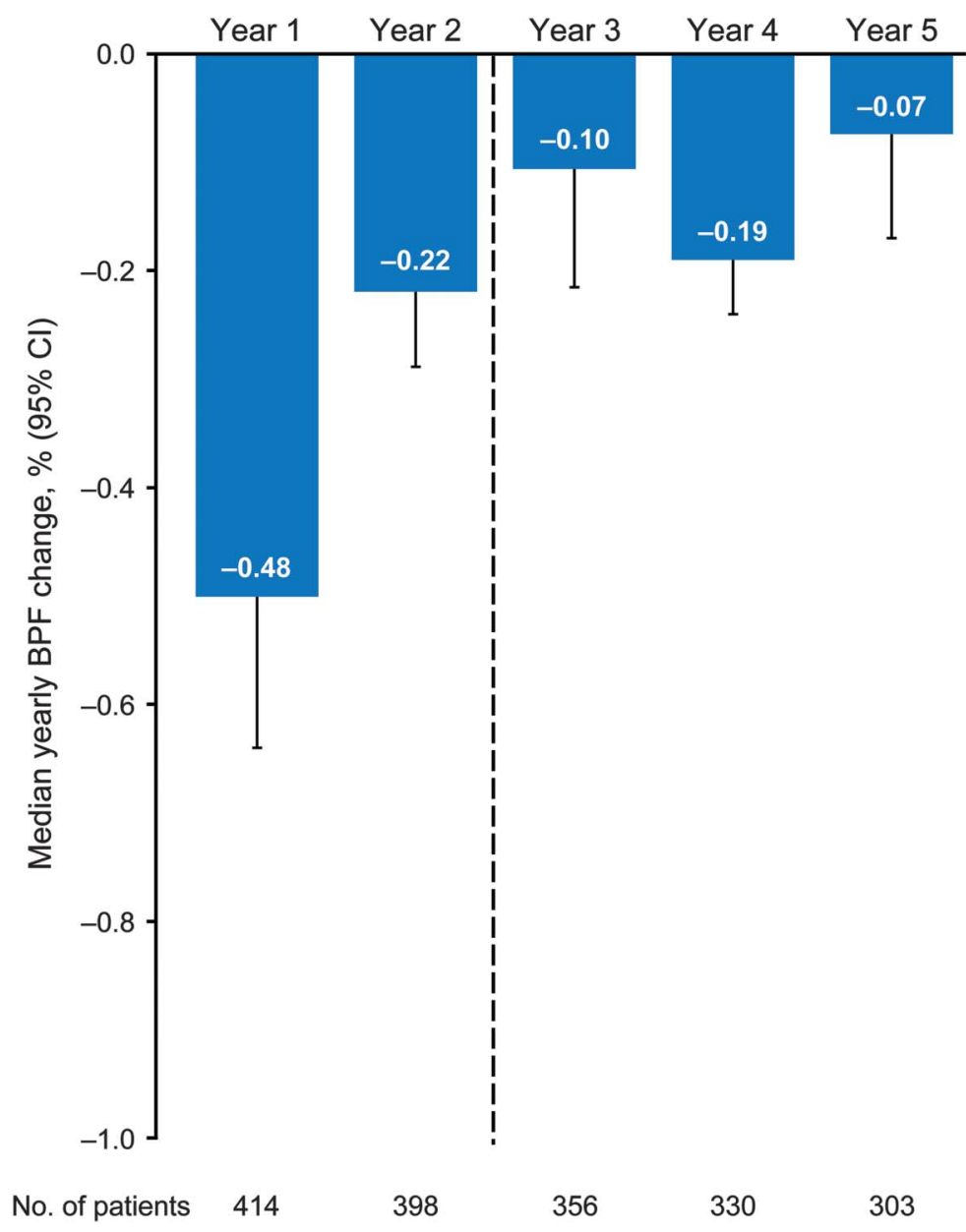

Median percentage yearly change in brain parenchymal fraction (BPF). Results are shown for patients who received alemtuzumab $12 \mathrm{mg}$ in the core study and enrolled in the extension. $\mathrm{Cl}=$ confidence interval.
Standard protocol approvals, registrations, and patient consents. This trial is registered with ClinicalTrials.gov (NCT00548405; NCT00930553). All procedures were approved by local institutional ethics review boards of participating sites. Patients provided written informed consent.

RESULTS Patients. A total of 435 patients received alemtuzumab $12 \mathrm{mg}$ in CARE-MS II; of 423 alemtuzumab-treated patients who completed CARE-MS II, 393 (92.9\%) entered the extension, of whom 357 (90.8\%) remained on study at month 60 (year 5; figure 1). Baseline characteristics of CAREMS II patients have been reported previously. ${ }^{8}$

In CARE-MS II, alemtuzumab patients received $12 \mathrm{mg} / \mathrm{d}$ at baseline (5 consecutive days) and 12 months later (3 consecutive days). Of the 393 patients who entered the extension, 17 received another DMT but no further alemtuzumab treatment during the extension. Of the remaining 376 patients, 218 $(58.0 \%)$ received just 2 courses of alemtuzumab, with $113(30.1 \%), 39(10.4 \%)$, and $6(1.6 \%)$ patients receiving 1, 2, or 3 additional courses, respectively, of alemtuzumab (table e-1 at Neurology.org). Relapse was the most common reason for alemtuzumab retreatment $(61.0 \%$ of retreatment courses for which a reason was provided); $16.1 \%$ of retreatments were prompted by MRI lesion activity and $22.9 \%$ by combined relapse and MRI lesion activity. Thirty patients (7.6\%) received $\geq 1$ other DMT (dimethyl fumarate $[\mathrm{n}=5$ ], fingolimod [5], glatiramer acetate [12], IFN$\beta-1 \mathrm{a}[1]$, IFN- $\beta-1 \mathrm{~b}[3]$, natalizumab [4], rituximab [4], or teriflunomide [3]); of these, 7 received more than 1 DMT (2 DMTs: 6 patients; 3 DMTs: 1 patient). Thirteen (3.3\%) patients received both alemtuzumab retreatment and another DMT.

Efficacy. ARR remained lower during each extension year and over years 3-5 than during the core study (figure 2A). Mean EDSS scores remained stable, with changes from core study baseline of $-0.20,-0.06$, 0.00 , and +0.06 for years $2-5$, respectively. Half of patients (51.7\%) had stable EDSS scores at year 5; $24.9 \%$ improved and $23.4 \%$ worsened (figure $2 \mathrm{~B}$ ). From baseline to year 5, 75.1\% (95\% confidence interval [CI] 70.5\%-79.2\%) of patients were free of 6-month CDW (i.e., 24.9\% [20.8\%-29.5\%] experienced 6-month $\mathrm{CDW}$ ), and $42.9 \%$ (95\% CI $37.4 \%-48.9 \%$ ) achieved 6-month CDI (figure 2C).

During each extension year, most alemtuzumabtreated patients showed no clinical disease activity or MRI lesion activity, and more than 50\% attained NEDA (figure 2D). Cumulatively in years 3-5, $51.8 \%$ were free of clinical disease activity, $48.6 \%$ showed no MRI lesion activity, and $27.0 \%$ showed neither clinical disease nor MRI lesion activity. Through each extension year, most patients were free of new Gd-enhancing or new/enlarging T2 


\begin{tabular}{|c|c|c|c|c|c|c|c|c|}
\hline & \multirow{2}{*}{\multicolumn{5}{|c|}{ Incidence, core and extension studies $(5 \mathrm{y}), \mathrm{n}(\%)^{\mathrm{a}}$}} & \multicolumn{3}{|c|}{$\begin{array}{l}\text { EAIR per } 100 \text { patient-years (no. of } \\
\text { events) }^{b}\end{array}$} \\
\hline & & & & & & \multirow{2}{*}{$\begin{array}{l}\begin{array}{l}\text { Core } \\
\text { study } \\
(2 \mathrm{y})\end{array} \\
\text { Years 0-2 } \\
(\mathrm{n}=435)\end{array}$} & \multirow{2}{*}{$\begin{array}{l}\text { Extension } \\
\text { study } \\
(3 \mathrm{y}) \\
\begin{array}{l}\text { Years 3-5 } \\
(\mathrm{n}=412)\end{array}\end{array}$} & \multirow{2}{*}{$\begin{array}{l}\begin{array}{l}\text { Core and } \\
\text { extension } \\
\text { studies } \\
(5 \mathrm{y})\end{array} \\
\begin{array}{l}\text { Years 0-5 } \\
(\mathrm{n}=435)\end{array}\end{array}$} \\
\hline & $\begin{array}{l}\text { Year } 1 \\
(n=435)\end{array}$ & $\begin{array}{l}\text { Year } 2 \\
(n=434)\end{array}$ & $\begin{array}{l}\text { Year } 3 \\
\left(n=412^{c}\right)\end{array}$ & $\begin{array}{l}\text { Year } 4 \\
(n=387)\end{array}$ & $\begin{array}{l}\text { Year } 5 \\
(n=367)\end{array}$ & & & \\
\hline Any AE excluding IARs ${ }^{d}$ & $373(85.7)$ & 379 (87.3) & $341(82.8)$ & $312(80.6)$ & $284(77.4)$ & 255.8 & 195.0 & 213.8 \\
\hline $\begin{array}{l}\text { AE leading to study drug } \\
\text { discontinuation }\end{array}$ & $9(2.1)$ & $5(1.2)$ & $1(0.2)$ & $3(0.8)$ & $2(0.5)$ & 1.6 & $0.4(5)$ & 1.0 \\
\hline Any serious $A E$ & 55 (12.6) & $43(9.9)$ & $39(9.5)$ & 53 (13.7) & $36(9.8)$ & 11.1 & 10.5 & 9.9 \\
\hline Any serious AE excluding IARs & 48 (11.0) & $41(9.4)$ & $39(9.5)$ & $53(13.7)$ & $34(9.3)$ & 10.0 & 10.4 & 9.2 \\
\hline Serious infections & $9(2.1)$ & $8(1.8)$ & $5(1.2)$ & $9(2.3)$ & $7(1.9)$ & 1.9 & 1.6 & 1.7 \\
\hline Any thyroid disorder ${ }^{e, f}$ & $31(7.1)$ & 40 (9.2) & 68 (16.5) & $23(5.9)$ & 12 (3.3) & 8.8 & 14.1 & 11.3 \\
\hline Serious thyroid AEs & 0 & $2(0.5)$ & $10(2.4)$ & $2(0.5)$ & $2(0.5)$ & $0.2(2)$ & 1.3 & $0.8(16)$ \\
\hline ITPe & $1(0.2)$ & $3(0.7)$ & $2(0.5)$ & $7(1.8)$ & $1(0.3)$ & $0.5(4)$ & $0.9(10)$ & $0.7(14)$ \\
\hline Nephropathye & 0 & $1(0.2)$ & 0 & 0 & 0 & $0.1(1)$ & 0 & $0.1(1)$ \\
\hline Malignant disease & 0 & $2(0.5)$ & $2(0.5)$ & 0 & 0 & $0.2(2)$ & $0.2(2)$ & $0.2(4)$ \\
\hline
\end{tabular}

Abbreviations: $\mathrm{AE}$ = adverse event; EAIR = exposure-adjusted incidence rate; IAR = infusion-associated reaction; ITP = immune thrombocytopenia. a Percentage is based on number of patients having an $A E$ in the reported year divided by the total number of patients followed up in that year.

${ }^{b}$ (Number of patients with a specific event divided by total exposure time among patients at risk of an initial occurrence of the event) $\times 100$. Events occurring in $<1$ per 100 patient-years include number of events in parentheses.

${ }^{c}$ In addition to the patients enrolled in the extension study, the safety analyses included a small number of core study patients ( $\mathrm{n}=19$ ) who did not enter the extension but were evaluated for AEs temporarily after the initial 2-year period.

${ }^{d}$ All patients with any $A E$, excluding those patients whose only AEs were IARs. IARs were any AE that occurred during the infusion or within 24 hours after the end of the infusion.

${ }^{\mathrm{e}}$ Includes first event by year of occurrence.

${ }^{f}$ Defined as any thyroid AE or abnormal thyroid-stimulating hormone level, with simultaneously abnormal free triiodothyronine $\left(T_{3}\right)$ or free thyroxine $\left(T_{4}\right)$ on the same visit.

hyperintense lesions (figure 2D) and new T1 hypointense lesions (year 3, 87.5\%; year 4, 86.3\%; year 5 , $87.5 \%)$.

Yearly BVL rate continued to decrease in year 3 compared with the core study, remaining low in years 4 and 5 (figure 3). Median BPF change from baseline to year 5 was $-0.855 \%$.

In the cohort of patients who achieved NEDA at year 2 and received no additional treatment (i.e., no alemtuzumab retreatment since the initial 2 courses and no other DMT [n = 141]; figure e-1A), most patients achieved NEDA in each extension year and 48.1\% attained sustained NEDA over years 2-5 (indicating that most patients were free of relapses, 6-month CDW, and new Gd-enhancing and T2 hyperintense lesions; figure e-1B); in these patients with sustained NEDA, BVL was also slowed (figure e-2).

Safety. Tables 1, 2, and e-2 summarize safety analyses for alemtuzumab-treated patients over 5 years up to the cutoff (1,986.7 patient-years). Overall incidences and EAIR of AEs were lower than in the core study; $96.2 \%$ of AEs were mild to moderate in severity. The EAIR of serious AEs was comparable to the core study. When AEs were assessed by treatment course, overall AE incidences for courses 3-5 were stable compared with courses 1-2 (table e-3). No patients discontinued from the extension study due to AEs. Two deaths, both unrelated to alemtuzumab treatment, were reported in the core study ${ }^{8}$; no deaths occurred during the extension.

Incidences of IARs and serious IARs for courses 3-5 were reduced compared with courses 1-2 (table 2). When IARs were included in overall AE counts, the EAIR was 871.3 in the core study and 201.3 in the extension; when IARs were removed, the EAIR remained lower in the extension (195.0) than in the core study (255.8; tables 1 and e-2). The most commonly reported IARs in the extension were headache, pyrexia, and rash. 
Table 2 Infusion-associated reaction (IAR) events through year 5 in patients treated with alemtuzumab $12 \mathrm{mg}$

\begin{tabular}{|c|c|c|c|c|c|c|c|}
\hline \multirow[b]{2}{*}{ IARs $^{\text {b }}$ by course } & \multicolumn{7}{|c|}{ Incidence, $\mathrm{n}(\%)^{\mathrm{a}}$} \\
\hline & $\begin{array}{l}\text { Course } 1 \\
(n=435)\end{array}$ & $\begin{array}{l}\text { Course } 2 \\
(n=421)\end{array}$ & $\begin{array}{l}\text { Course } 3 \\
(n=158)\end{array}$ & $\begin{array}{l}\text { Course } 4 \\
(n=45)\end{array}$ & $\begin{array}{l}\text { Course } 5 \\
(n=6)\end{array}$ & $\begin{array}{l}\text { Patients receiving } \\
\text { initial } 2 \text { courses, } \\
\text { courses } 1-2(n=435)\end{array}$ & $\begin{array}{l}\text { Patients receiving } \\
\text { retreatment, } \\
\text { courses } 3-5(n=158)\end{array}$ \\
\hline Any IAR & 364 (83.7) & 300 (71.3) & 101 (63.9) & 31 (68.9) & 3 (50.0) & 393 (90.3) & $108(68.4)$ \\
\hline \multicolumn{8}{|c|}{$\begin{array}{l}\text { IAR events affecting }>10 \% \text { of } \\
\text { patients over courses } 1-5\end{array}$} \\
\hline $\operatorname{Rash}^{\mathrm{c}}$ & $163(37.5)$ & $72(17.1)$ & $17(10.8)$ & $5(11.1)$ & $1(16.7)$ & 181 (41.6) & 19 (12.0) \\
\hline Nausea & 51 (11.7) & $36(8.6)$ & $12(7.6)$ & $4(8.9)$ & 0 & 72 (16.6) & $15(9.5)$ \\
\hline Pyrexia & $43(9.9)$ & $41(9.7)$ & $18(11.4)$ & $5(11.1)$ & $1(16.7)$ & 69 (15.9) & 21 (13.3) \\
\hline Urticaria & 57 (13.1) & $24(5.7)$ & $7(4.4)$ & $4(8.9)$ & 0 & $64(14.7)$ & $10(6.3)$ \\
\hline Flushing & $28(6.4)$ & $13(3.1)$ & $8(5.1)$ & 5 (11.1) & $1(16.7)$ & $34(7.8)$ & $14(8.9)$ \\
\hline Serious IARs ${ }^{e}$ & $6(1.4)$ & $6(1.4)$ & 2 (1.3) & 0 & 0 & $12(2.8)$ & $2(1.3)$ \\
\hline
\end{tabular}

a Percentage is based on number of patients having an IAR in the reported course divided by total number of patients followed up for that course.

${ }^{\mathrm{b}}$ IARs were any adverse event that occurred during the infusion or within 24 hours after the end of the infusion.

${ }^{\mathrm{c}}$ Rash includes the preferred terms rash and rash generalized.

${ }^{\mathrm{d}}$ Pruritus includes the preferred terms pruritus and pruritus generalized.

e The following serious IARs occurred in 2 patients each: pyrexia (course 1), urticaria (course 1). The following serious IARs occurred in 1 patient each: chest discomfort (course 1), chest pain (course 1), cough (course 1), dyspnea (course 2), edema peripheral (course 2), hemoptysis (course 2), headache (course 3), hypothyroidism (course 2), infusion-related reaction (course 2), nausea (course 2), noncardiac chest pain (course 2), postlumbar syndrome (course 3), status migrainosus (course 2), trigeminal neuralgia (course 3), vomiting (course 2). No serious IARs occurred in courses 4 or 5.

Infection $\mathrm{AE}$ incidences and EAIRs declined from the core study to the extension (tables 1 and e-2), and incidences did not increase with successive alemtuzumab courses (table e-3); $97.7 \%$ of infections in years 3-5 were mild to moderate. As in the core study, the most common infections were nasopharyngitis, urinary tract infection, and upper respiratory tract infection. Herpetic infections were predominantly mucocutaneous and most frequent in the first month after alemtuzumab treatment. Serious infection incidences in the extension were stable compared with the core study.

The most common autoimmune AEs were thyroid AEs (5-year incidence: 37.7\%); incidences peaked in year $3(17.0 \%)$ compared with years 1 $(5.1 \%)$ and $2(8.8 \%)$, and declined in years 4 $(5.4 \%)$ and $5(3.5 \%)$. A similar incidence pattern was observed for the more comprehensive classification of thyroid disorders (thyroid AEs combined with abnormal thyroid function test), peaking at year 3 and declining thereafter (tables 1 and e-2; 5-year incidence: $40.0 \%)$. Serious thyroid AE incidences were $<2.5 \%$ during each year. Thirteen patients underwent thyroidectomy during the extension, most of whom were subsequently maintained on thyroxine.

Ten new cases of ITP were reported during the extension ( $\mathrm{n}=2,7$, and 1 , in years 3,4 , and 5 , respectively). Cases were detected based on clinical signs (e.g., presence of petechiae but no major hemorrhage) or low platelets from laboratory monitoring, and responded to therapy including steroids and/or IV immunoglobulin, or rituximab.

No new nephropathy cases developed during the extension. During the core trial, as reported previously, ${ }^{8}$ one patient developed membranous glomerulonephritis, with proteinuria, microhematuria, and hypoalbuminemia, but normal serum creatinine. Nephropathy persisted during the extension and 4 concomitant medications for nephrotic syndrome were administered (furosemide, valsartan, metolazone, and oral potassium chloride). Serum creatinine level remained normal.

Two malignancies (papillary thyroid microcarcinoma and melanoma) were reported in years 3-5. Over 5 years, a total of 4 malignancies were reported ( 1 case of thyroid cancer and 1 case of basal cell carcinoma occurred in the core study; EAIR of 0.2 per 100 patient-years).

EAIRs in the pooled alemtuzumab 12- and 24-mg groups (596 patients) were similar to those for the 12-mg group (table e-4).

DISCUSSION Events that occur early in MS, including subclinical inflammation, contribute to potentially permanent disability later in the disease course. $^{10,11}$ Patients with disease activity while 
receiving modest-efficacy DMT may have clinical exacerbations with adverse long-term implications. ${ }^{12-}$

14 In such patients, few data exist to inform the decision between continuing their current therapy or switching to more efficacious treatment, ${ }^{15-20}$ although several studies have shown that timely switching to high-efficacy DMTs reduces relapse rates and disability accumulation. ${ }^{12,13}$ Moreover, DMT switching must be considered for patients who develop new risk factors, resulting in a less favorable benefit:risk balance of the current therapy. The CARE-MS II trial enrolled patients with disease activity during IFN- $\beta$ or glatiramer acetate treatment, and compared efficacy and safety over 2 years of further modest-efficacy DMT (SC IFN- $\beta$-1a) against switching to alemtuzumab. Here we describe long-term outcomes of patients from the CARE-MS II alemtuzumab arm who participated in an extension, with 5 total years of follow-up.

Our results demonstrate that reductions in disease activity and cerebral atrophy with alemtuzumab continue over 5 years. ARR remained low over 5 years, and most patients had stable or improved EDSS scores and were free of 6-month CDW; $43 \%$ achieved 6-month CDI. The improvements in preexisting disability with alemtuzumab are noteworthy. During years 3, 4, and 5, most patients had no clinical or MRI lesion activity and were free of active lesions, and the majority of patients achieved NEDA; about a quarter of this population with an inadequate response to prior therapy met the more challenging endpoint of sustained NEDA throughout the extension (years 3-5).

Cerebral atrophy occurs at a faster rate among patients with MS compared with healthy individuals and correlates with poorer clinical outcomes, including long-term physical and cognitive impairment. ${ }^{21-27}$ Therefore, slowing of brain atrophy has emerged as a clinically relevant outcome for RRMS. Alemtuzumab slowed annual BVL throughout years 3-5, and cumulative BVL over 5 years in alemtuzumab-treated patients was less than in patients who received core study SC IFN- $\beta-1 \mathrm{a}$ and then switched to alemtuzumab in the extension (median BPF changes of $-0.855 \%$ vs $-1.044 \%$, respectively). ${ }^{28}$ These findings further support the long-term benefits of earlier alemtuzumab treatment and may indicate potential neuroprotective effects.

The continued efficacy of alemtuzumab during the extension was accompanied by a safety profile that was consistent with prior studies. ${ }^{6-8}$ As expected based on phase 2 data, ${ }^{29}$ the incidence of autoimmune thyroid AEs peaked in year 3, declining thereafter. Incidences of other autoimmune AEs, including ITP, were much lower. Malignancies remained infrequent over 5 years. Two papillary thyroid carcinomas were discovered incidentally during imaging for thyroid dysfunction. ${ }^{30,31}$ It is unknown whether these tumors would be characterized differently using recent reclassification criteria. $^{32}$ Overall, AEs decreased over time after alemtuzumab treatment, in contrast to some other DMTs, which are associated with known risks that remain constant or increase with chronic exposure to the drug. ${ }^{33-35}$ Monthly laboratory monitoring and effective management of potential AEs mitigate the risks of alemtuzumab to maximize therapeutic benefit.

Limitations of our study include the potential for bias due to open-label aspects of its design; however, rater blinding was maintained for disability and imaging assessments, and the results of those endpoints were fully consistent with the observed relapse outcomes and with those of the rater-blinded core phase 3 study. Although comparator therapy was not continued into the extension, so there is no control group for the long-term data, the clinical and imaging benefits observed with alemtuzumab during the extension were maintained or even improved compared with the core study. This would not be expected if treatment were ineffective, especially given that all patients had active RRMS on prior therapy before initiation of alemtuzumab. Selection bias could arise as participation in the extension was voluntary. However, the patient retention rate in our study $(>90 \%)$ was unusually high compared with extension studies of other MS DMTs (range 68\%$84 \%) .{ }^{36-38}$ Of potential relevance to maintaining such a high retention rate is the fact that persisting efficacy was achieved in the absence of continuous treatment, which contrasts with the reported loss of efficacy following cessation of other MS therapies. ${ }^{39,40}$

Reducing clinically manifest MS disease activity and altering the downward trajectory of MS-related brain atrophy are critical to avoid potentially permanent loss of function and a declining quality of life. Our study reports long-term maintenance of alemtuzumab's therapeutic effects on stringent clinical and MRI lesion outcomes and brain atrophy. Risks accompanying such beneficial effects may be mitigated effectively when patients and physicians are vigilant to early symptoms and adhere to the safety monitoring program. As efficacy was maintained while the incidence of most AEs declined over time, the evolving benefit-risk balance shifted favorably over time. We suggest that alemtuzumab constitutes a unique treatment approach that can provide durable efficacy in the absence of continuous dosing, and with manageable adverse effects.

\section{AUTHOR CONTRIBUTIONS}

A.J.C., J.A.C., E.J.F., G.G., H.-P.H., E.H., S.S., K.W.S., A.T., and D.A.S.C. contributed to study design, data collection, and writing and 
critical review of the manuscript and approved the final submission draft. D.L.A. contributed to data collection and writing and critical review of the manuscript and approved the final submission draft. D.H.M. and M.A.P. contributed to study design and writing and critical review of the manuscript and approved the final submission draft. M.C.C. and D.J. contributed to writing and critical review of the manuscript and approved the final submission draft. K.T. led the statistical support, contributed to the writing and critical review of the manuscript, and approved the final submission draft. P.X. and R.J.H. provided editorial and medical writing support (assistance in drafting the manuscript, technical editing, copyediting, and responding to reviewers' comments) and approved the final submission draft.

\section{ACKNOWLEDGMENT}

Critical review of the manuscript was provided by Darren P. Baker, PhD, Maria Melanson, MD, PhD, Claudio E. Rodriguez, MD, and Sarah Strattman, MS, of Sanofi; and by Vladimir Evilevitch, MD, $\mathrm{PhD}$, who was an employee of Sanofi at the time of his review. Kunio Nakamura, PhD, oversaw BPF analyses and was an employee of the Department of Biomedical Engineering, Cleveland Clinic, $\mathrm{OH}$, at the time the work was conducted. Statistical support was provided by Linda Kasten, BS, MA, who received compensation (Sanofi) as an employee of PROMETRIKA, LLC, when the statistical analyses were performed; currently an employee of Biostatistical Consulting, Inc. Catherine Pennella, BS, of Sanofi Genzyme assisted in safety analyses. The CARE-MS studies and their extension study were sponsored by Sanofi and Bayer HealthCare Pharmaceuticals.

\section{STUDY FUNDING}

Supported by Sanofi and Bayer HealthCare Pharmaceuticals.

\section{DISCLOSURE}

A.J. Coles reports receiving consulting fees, lecture fees, and institutional grant support from Sanofi Genzyme. J.A. Cohen reports personal compensation for consulting for Genentech, Merck, Novartis, and Receptos and as a Co-Editor of Multiple Sclerosis Journal-Experimental, Translational and Clinical. E.J. Fox reports receiving consulting fees, honoraria, travel, and research support from Acorda, Bayer HealthCare, Biogen, EMD Serono, Genentech, Novartis, Opexa Therapeutics, Sanofi Genzyme, and Teva. G. Giovannoni reports having served as a consultant or received research support from AbbVie, Bayer HealthCare, Biogen, Canbex Therapeutics, Five Prime Therapeutics, GlaxoSmithKline, GW Pharma, Merck Serono, Novartis, Oxford PharmaGenesis, Protein Discovery Laboratories, Roche, Sanofi Genzyme, Synthon, Teva, and UCB. H.-P. Hartung reports receiving honoraria for consulting and speaking at symposia from Bayer HealthCare, Biogen, CSL Behring, Grifols, Merck Serono, Novartis, Roche, and Sanofi Genzyme. E. Havrdova reports receiving honoraria and grant support from Actelion, Biogen, Merck Serono, Novartis, Receptos, Roche, Sanofi Genzyme, and Teva, and is supported by Ministry of Education of Czech Republic, project PROGRES Q27/LF1. S. Schippling reports receiving research grant from Novartis and Sanofi Genzyme and consulting and speaking fees from Biogen, Merck Serono, Novartis, Sanofi Genzyme, and Teva. K.W. Selmaj reports receiving consulting fees from Biogen, Merck, Novartis, Roche, Sanofi Genzyme, and Synthon. A. Traboulsee report receiving consulting fees from Biogen, Novartis, Roche, Sanofi Genzyme, Serono, and Teva Innovation and has been a principal investigator on clinical trials funded by Roche and Sanofi Genzyme. D.A.S. Compston reports receiving consulting fees and grant support from Genzyme and lecture fees from Bayer Schering Pharma on behalf of the University of Cambridge and personal remuneration for lecture fees from Genzyme from July 2014. D.H. Margolin, K. Thangavelu, M.C. Chirieac, and D. Jody report receiving personal compensation as employees of Sanofi R.J. Hogan and P. Xenopoulos report receiving personal compensation as employees of Envision Scientific Solutions. M.A. Panzara received personal compensation as an employee of Sanofi during study conduct and analysis and during preparation of the manuscript. D.L. Arnold reports receiving compensation for serving as a speaker, consultant, and advisory board participant and receiving research support from Acorda, Bayer, Biogen, Eli Lilly, EMD Serono, Genentech, GlaxoSmithKline,
MedImmune, Merck Serono, NeuroRx Research, Novartis, Opexa Therapeutics, Receptos, Roche, Sanofi Genzyme, Teva, the Canadian Institutes of Health Research, and the Multiple Sclerosis Society of Canada. Go to Neurology.org for full disclosures.

Received August 9, 2016. Accepted in final form June 22, 2017.

\section{REFERENCES}

1. Cox AL, Thompson SA, Jones JL, et al. Lymphocyte homeostasis following therapeutic lymphocyte depletion in multiple sclerosis. Eur J Immunol 2005;35:3332-3342.

2. Havari E, Turner MJ, Campos-Rivera J, et al. Impact of alemtuzumab treatment on the survival and function of human regulatory $\mathrm{T}$ cells in vitro. Immunology 2014;141: $123-131$.

3. LEMTRADA [summary of product characteristics] [online]. Available at: ema.europa.eu/docs/en_GB/ document_library/EPAR_-_Product_Information/ human/003718/WC500150521.pdf. Accessed May 30, 2014 .

4. LEMTRADA (Alemtuzumab), for Intravenous Injection [prescribing information]. Cambridge, MA: Genzyme Corporation; 2014.

5. Hartung HP, Aktas O, Boyko AN. Alemtuzumab: a new therapy for active relapsing-remitting multiple sclerosis. Mult Scler 2015;21:22-34.

6. CAMMS223 Trial Investigators, Coles AJ, Compston $\mathrm{DA}$, et al. Alemtuzumab vs. interferon beta-1a in early multiple sclerosis. N Engl J Med 2008;359:1786-1801.

7. Cohen JA, Coles AJ, Arnold DL, et al. Alemtuzumab versus interferon beta $1 \mathrm{a}$ as first-line treatment for patients with relapsing-remitting multiple sclerosis: a randomised controlled phase 3 trial. Lancet 2012;380:1819-1828.

8. Coles AJ, Twyman CL, Arnold DL, et al. Alemtuzumab for patients with relapsing multiple sclerosis after diseasemodifying therapy: a randomised controlled phase 3 trial. Lancet 2012;380:1829-1839.

9. Liu GF, Wang J, Liu K, Snavely DB. Confidence intervals for an exposure adjusted incidence rate difference with applications to clinical trials. Stat Med 2006;25:1275-1286.

10. Compston A, Coles A. Multiple sclerosis. Lancet 2008; 372:1502-1517.

11. Stys PK, Zamponi GW, van Minnen J, Geurts JJ. Will the real multiple sclerosis please stand up? Nat Rev Neurosci 2012;13:507-514.

12. Rio J, Tintore M, Sastre-Garriga J, et al. Change in the clinical activity of multiple sclerosis after treatment switch for suboptimal response. Eur J Neurol 2012;19: 899-904.

13. Kalincik T, Horakova D, Spelman T, et al. Switch to natalizumab versus fingolimod in active relapsingremitting multiple sclerosis. Ann Neurol 2015;77: 425-435.

14. He A, Spelman T, Jokubaitis V, et al. Comparison of switch to fingolimod or interferon beta/glatiramer acetate in active multiple sclerosis. JAMA Neurol 2015;72: 405-413.

15. Putzki N, Yaldizli O, Maurer M, et al. Efficacy of natalizumab in second line therapy of relapsing-remitting multiple sclerosis: results from a multi-center study in German speaking countries. Eur J Neurol 2010;17:31-37.

16. Oturai AB, Koch-Henriksen N, Petersen T, Jensen PE, Sellebjerg F, Sorensen PS. Efficacy of natalizumab in multiple sclerosis patients with high disease activity: a Danish nationwide study. Eur J Neurol 2009;16:420-423. 
17. Jokubaitis VG, Li V, Kalincik T, et al. Fingolimod after natalizumab and the risk of short-term relapse. Neurology 2014;82:1204-1211.

18. Castillo-Trivino T, Mowry EM, Gajofatto A, et al. Switching multiple sclerosis patients with breakthrough disease to second-line therapy. PLoS One 2011;6:e16664.

19. Bergvall N, Makin C, Lahoz R, et al. Relapse rates in patients with multiple sclerosis switching from interferon to fingolimod or glatiramer acetate: a US claims database study. PLoS One 2014;9:e88472.

20. Cohen M, Maillart E, Tourbah A, et al. Switching from natalizumab to fingolimod in multiple sclerosis: a French prospective study. JAMA Neurol 2014;71:436-441.

21. Khaleeli Z, Ciccarelli O, Manfredonia F, et al. Predicting progression in primary progressive multiple sclerosis: a 10 year multicenter study. Ann Neurol 2008;63:790-793.

22. Fisher E, Nakamura K, Lee JC, You X, Sperling B, Rudick RA. Effect of intramuscular interferon beta-1a on gray matter atrophy in relapsing-remitting multiple sclerosis: a retrospective analysis. Mult Scler 2016;22:668-676.

23. De Stefano N, Airas L, Grigoriadis N, et al. Clinical relevance of brain volume measures in multiple sclerosis. CNS Drugs 2014;28:147-156.

24. Sastre-Garriga J, Ingle GT, Rovaris M, et al. Long-term clinical outcome of primary progressive MS: predictive value of clinical and MRI data. Neurology 2005;65: 633-635.

25. Zivadinov R, Sepcic J, Nasuelli D, et al. A longitudinal study of brain atrophy and cognitive disturbances in the early phase of relapsing-remitting multiple sclerosis. J Neurol Neurosurg Psychiatry 2001;70:773-780.

26. Zivadinov R, Uher T, Hagemeier J, et al. A serial 10-year follow-up study of brain atrophy and disability progression in RRMS patients. Mult Scler 2016;22:1709-1718.

27. Popescu V, Agosta F, Hulst HE, et al. Brain atrophy and lesion load predict long term disability in multiple sclerosis. J Neurol Neurosurg Psychiatry 2013;84:1082-1091.

28. Barkhof F, Cohen JA, Coles A, et al. RRMS patients switching from SC IFNB-1a to alemtuzumab in the CARE-MS I and II extension study have a reduced rate of brain volume loss (P6.183). Neurology 2016;86:16.

29. Coles AJ, Fox E, Vladic A, et al. Alemtuzumab more effective than interferon beta-1a at 5-year follow-up of
CAMMS223 clinical trial. Neurology 2012;78:10691078.

30. Ahn HS, Kim HJ, Welch HG. Korea's thyroid-cancer "epidemic": screening and overdiagnosis. N Engl J Med 2014;371:1765-1767.

31. Schneider DF, Chen H. New developments in the diagnosis and treatment of thyroid cancer. CA Cancer J Clin 2013;63:374-394.

32. Nikiforov YE, Seethala RR, Tallini G, et al. Nomenclature revision for encapsulated follicular variant of papillary thyroid carcinoma: a paradigm shift to reduce overtreatment of indolent tumors. JAMA Oncol 2016;2:1023-1029.

33. Butzkueven H, Kappos L, Pellegrini F, et al. Efficacy and safety of natalizumab in multiple sclerosis: interim observational programme results. J Neurol Neurosurg Psychiatry 2014;85:1190-1197.

34. O'Connor P, Goodman A, Kappos L, et al. Long-term safety and effectiveness of natalizumab redosing and treatment in the STRATA MS Study. Neurology 2014;83: 78-86.

35. Bloomgren G, Richman S, Hotermans C, et al. Risk of natalizumab-associated progressive multifocal leukoencephalopathy. N Engl J Med 2012;366:1870-1880.

36. Cohen JA, Khatri B, Barkhof F, et al. Long-term (up to 4.5 years) treatment with fingolimod in multiple sclerosis: results from the extension of the randomised TRANSFORMS study. J Neurol Neurosurg Psychiatry 2016;87:468-475.

37. Gold R, Arnold DL, Bar-Or A, et al. Long-term effects of delayed-release dimethyl fumarate in multiple sclerosis: interim analysis of ENDORSE, a randomized extension study. Mult Scler 2017;23:253-265.

38. Kappos L, O'Connor P, Radue EW, et al. Long-term effects of fingolimod in multiple sclerosis: the randomized FREEDOMS extension trial. Neurology 2015;84:15821591.

39. Hatcher SE, Waubant E, Nourbakhsh B, CrabtreeHartman E, Graves JS. Rebound syndrome in patients with multiple sclerosis after cessation of fingolimod treatment. JAMA Neurol 2016;73:790-794.

40. Rasenack M, Derfuss T. Disease activity return after natalizumab cessation in multiple sclerosis. Expert Rev Neurother 2016;16:587-594.

\section{Neurology MOC Prep Course-Now Available Online and In-person!}

Recertification approaching? Looking for a comprehensive review in key areas of clinical neurology? Prepare for the ABPN recertification exam in clinical neurology by attending a Neurology MOC Prep Course-now offered in both in-person and online formats to meet your preferred learning style. Learn more at $A A N$.com/view/MOCPrep. 


\title{
Neurology
}

\begin{abstract}
Alemtuzumab CARE-MS II 5-year follow-up: Efficacy and safety findings Alasdair J. Coles, Jeffrey A. Cohen, Edward J. Fox, et al.

Neurology 2017;89;1117-1126 Published Online before print August 23, 2017

DOI 10.1212/WNL.0000000000004354
\end{abstract}

This information is current as of August 23, 2017

Neurology ${ }^{\circledR}$ is the official journal of the American Academy of Neurology. Published continuously since 1951, it is now a weekly with 48 issues per year. Copyright Copyright (C) 2017 The Author(s). Published by Wolters Kluwer Health, Inc. on behalf of the American Academy of Neurology. All rights reserved. Print ISSN: 0028-3878. Online ISSN: 1526-632X.

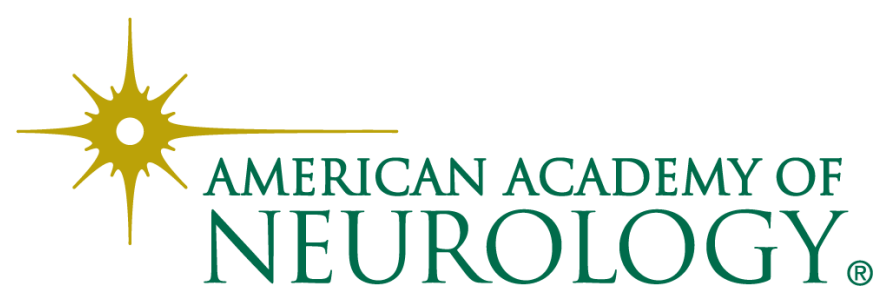




\section{Updated Information \& Services}

\section{Supplementary Material}

\section{References}

\section{Citations}

Subspecialty Collections

\section{Permissions \& Licensing}

\section{Reprints}

including high resolution figures, can be found at: http://n.neurology.org/content/89/11/1117.full

Supplementary material can be found at: http://n.neurology.org/content/suppl/2017/08/23/WNL.0000000000004 354.DC1

http://n.neurology.org/content/suppl/2017/08/23/WNL.0000000000004 354.DC2

http://n.neurology.org/content/suppl/2017/08/23/WNL.0000000000004 354.DC3

This article cites 38 articles, 9 of which you can access for free at: http://n.neurology.org/content/89/11/1117.full\#ref-list-1

This article has been cited by 11 HighWire-hosted articles: http://n.neurology.org/content/89/11/1117.full\#\#otherarticles

This article, along with others on similar topics, appears in the following collection(s):

Autoimmune diseases

http://n.neurology.org/cgi/collection/autoimmune_diseases

\section{Class III}

http://n.neurology.org/cgi/collection/class_iii

Clinical trials Randomized controlled (CONSORT agreement) http://n.neurology.org/cgi/collection/clinical_trials_randomized_control led_consort_agreement

Multiple sclerosis

http://n.neurology.org/cgi/collection/multiple_sclerosis

Information about reproducing this article in parts (figures,tables) or in its entirety can be found online at:

http://www.neurology.org/about/about_the_journal\#permissions

Information about ordering reprints can be found online:

http://n.neurology.org/subscribers/advertise

Neurology ${ }^{\circledR}$ is the official journal of the American Academy of Neurology. Published continuously since 1951, it is now a weekly with 48 issues per year. Copyright Copyright ( 2017 The Author(s). Published by Wolters Kluwer Health, Inc. on behalf of the American Academy of Neurology. All rights reserved. Print ISSN: 0028-3878. Online ISSN: 1526-632X.

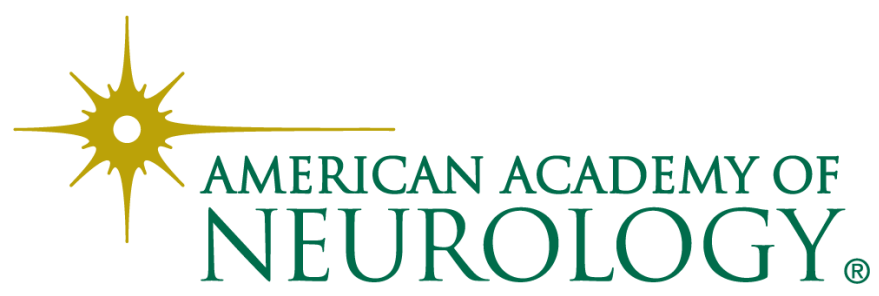

